\title{
Badanie zależności zapachowej jakości powietrza od zawartości zanieczyszczeń siarkowych z użyciem przystawki odorymetrycznej INiG - PIB
}

\begin{abstract}
$\mathrm{W}$ artykule poruszono zagadnienia związane z badaniami jakości zapachowej powietrza atmosferycznego. Dokonano niezbędnego przeglądu literatury dotyczącej źródeł emisji zanieczyszczeń zapachowych powietrza atmosferycznego, metod poboru jego próbek, a także metod badania zapachu. W toku badań eksperymentalnych opracowano krzywe kalibracyjne wybranych zanieczyszczeń siarkowych powietrza dla analizatora chromatograficznego z detektorem elektrochemicznym. Przeprowadzono badania oznaczania intensywności zapachowej syntetycznych próbek powietrza atmosferycznego oraz zawartości zanieczyszczeń zapachowych w tych próbkach.
\end{abstract}

Słowa kluczowe: chromatografia gazowa, odory, zanieczyszczenia powietrza atmosferycznego.

\section{Study on the scent of air quality of the concentration of sulfur contaminants with odorimeter snap}

\begin{abstract}
The article presents recent research on the scent quality of atmospheric air. The necessary review of literature concerning sources of emissions of scented air, methods of air sampling and methods for testing odor was made. In the experimental research, calibration curves for sulfur pollutants of air were developed by using a chromatographic analyzer with electrochemical detector. Studies were conducted for determining the intensity of synthetic air samples and the scent impurity content in these samples.
\end{abstract}

Key words: gas chromatography, odors, air pollution.

\section{Wprowadzenie}

$\mathrm{Na}$ bazie prac prowadzonych w Zakładzie Nawaniania Paliw Gazowych INiG - PIB, w zakresie konstrukcji i testów przystawki odorymetrycznej sprzężonej z analizatorem chromatograficznym z detektorem elektrochemicznym [4], podjęto próby badań zapachowej jakości powietrza atmosferycznego. Układ GC-O (chromatograf gazowy - przystawka odorymetryczna) stanowi jedną z nowoczesnych technik pomiarów zapachu, określaną mianem chromatograficzno-gazowej olfaktometrii rozcieńczeniowej.

Obecnie w Polsce, jak i wielu innych krajach, nie istnieją akty prawne regulujące obszar jakości zapachowej powietrza atmosferycznego. Kwestia uciążliwych zapachów/ odorów stanowi jedną z najtrudniejszych do uregulowania, a obecny stan wiedzy na ten temat jest zbyt ubogi. Znaczne problemy w trakcie prac nad wprowadzeniem przepisów stwarza metoda prowadzenia pomiarów uciążliwości zapachowej podmiotów emitujących odory [7]. Zatem istnieją duże możliwości dla rozwoju metod badawczych w zakresie pomiarów uciążliwości zapachowej powietrza atmosferycznego.

Wśród zanieczyszczeń gazowych sporą grupę stanowią odoranty, czyli substancje powodujące zanieczyszczenia zapachowe. Na nich skupiona jest niniejsza publikacja, z uwagi na obszar tematyki, jakim zajmuje się Zakład Nawaniania Paliw Gazowych INiG - PIB, w którym zrealizowano opisane poniżej badania dotyczące zapachowych zanieczyszczeń powietrza.

Odoranty to lotne substancje mające zdolność pobudzania komórek nerwowych nabłonka węchowego. W wyniku tej interakcji w mózgu dochodzi do odczytania danego 
wrażenia węchowego. Szczegółowe mechanizmy działania zmysłu powonienia wciąż nie zostały do końca wyjaśnione. Prowadzone badania umożliwiają m.in.: wyodrębnienie czynników decydujących o wpływie zapachów na organizm ludzki, opis cech zapachu, zdefiniowanie uciążliwości zapachowej oraz określenie jej parametrów [8].

Niepożądane zapachy - odory mogą wywoływać wiele negatywnych skutków, w tym m.in.:
- pogorszenie jakości środowiska naturalnego,

- szkody w świecie roślin, życiu zwierząt, mieniu,

- dyskomfort,

- pogorszenie bezpieczeństwa i jakości życia,

- utratę możliwości prawidłowego użytkowania nieruchomości,

- zakłócenia normalnego prowadzenia działalności gospodarczej.

\section{Najbardziej uciążliwe źródła odorantów}

Działalność człowieka jest najczęstszym źródłem odorów. Pod tym względem najbardziej uciążliwe są [2, 5, 8]:

- składowiska odpadów komunalnych:

skład odorantów w biogazie wysypiskowym jest urozmaicony. Są tam mono- i dimetyloaminy oraz ich etylowe analogi, siarkowodór, metano-, etano-, i-butanotiole, kwas mrówkowy, octowy, propionowy i alkohole niższe, tj. metanol, etanol i n-butanol. Najbardziej uciążliwe zapachowo są siarkowodór i alkilotiole;

- oczyszczalnie ścieków:

powstające w wyniku biodegradacji odory swoim składem są zbliżone do biogazu wysypiskowego; występują wśród nich siarkowodór, alkilotiole, sulfidy, disulfidy alkilowe, amoniak, aminy, aldehydy i ketony, kwasy tłuszczowe.

- przemysł paliwowy i przemysł przetwórstwa ropy naftowej:

surowcem podlegającym przetwórstwu jest ropa naftowa zanieczyszczona siarką i jej związkami oraz substancjami smolistymi. W wyniku różnych reakcji powstają tiole, sulfidy, disulfidy alkilowe, aromatyczne oraz mono- i bicykliczne [6];

- przemysł celulozowo-papierniczy:

głównym źródłem odorów, powstających na skutek stosowania siarczków nieorganicznych i ługów, są procesy wytwarzania celulozy siarczanowej. W kolejnych fazach tego procesu także powstają związki odorotwórcze, takie jak: siarkowodór, metylotiol, sulfidy i disulfidy alkilowe, aceton, metanol, etanol, związki terpenowe czy olej talowy.
Wyjątkowo duże ilości odorów wydzielają się w warzelniach $\mathrm{w}$ trakcie roztwarzania drewna oraz w wyparkach pulpy celulozowej;

- produkcja kwasu fosforowego:

jest źródłem emisji tioli, sulfidów oraz siarkowodoru;

- hodowla zwierzęca i roślinna: procesy gnilne odpadów pochodzących z produkcji są źródłem emisji głównie związków siarki i azotu;

- przetwórstwo spożywcze:

rodzaj emitowanych odorów zależy od rodzaju produkcji, najbardziej uciążliwe jest przetwórstwo mięsa oraz ryb (związki azotu).

Analizując przedstawione powyżej informacje, można zidentyfikować najpowszechniej występujące i najbardziej uciążliwe zapachowo odoranty. Są nimi lotne związki siarki. Charakteryzują się one wyjątkowo nieprzyjemnym zapachem, który potęgowany jest przez niski próg jego wyczuwalności $[1,2]$. Zauważyć można, że lotne związki siarki charakteryzują się znacznie niższymi poziomami wyczuwalności zapachu niż inne lotne odoranty, takie jak amoniak czy kwasy organiczne, które również należną do grupy odorantów często występujących w powietrzu atmosferycznym. Dodatkowo związki siarki emitowane są w dużej ilości przez wysypiska odpadów komunalnych i oczyszczalnie ścieków, czyli obiekty, które zlokalizowane są w pobliżu niemalże każdej miejscowości. Tak więc naturalnym jest skupienie uwagi właśnie na odorantach siarkowych w kontekście rozwijania metod badań zapachowej jakości powietrza.

\section{Przegląd metod badawczych zapachowej jakości powietrza}

W celu przedstawienia metod przeprowadzania badań zapachowej jakości powietrza, konieczne jest ustalenie modelu opisu ilościowego zagadnienia. Nie jest to łatwe, gdyż zapach to wrażenie zmysłowe, a przez to trudne do opisu ilościowego. W badaniach nad związkami odorotwórczymi/ odorantami oraz w próbach zmierzających do opisu i oceny zjawiska uciążliwości zapachowej uwzględniane są trzy podstawowe cechy zapachu:
- stężenie zapachowe,

- intensywność zapachu,

- jakość hedoniczna zapachu.

W monitoringu związków odorotwórczych dominują przede wszystkim:

- urządzenia wieloczujnikowe (identyfikacja poszczególnych składników mieszaniny),

- techniki chromatograficzne (określenie stężenia odoro- 


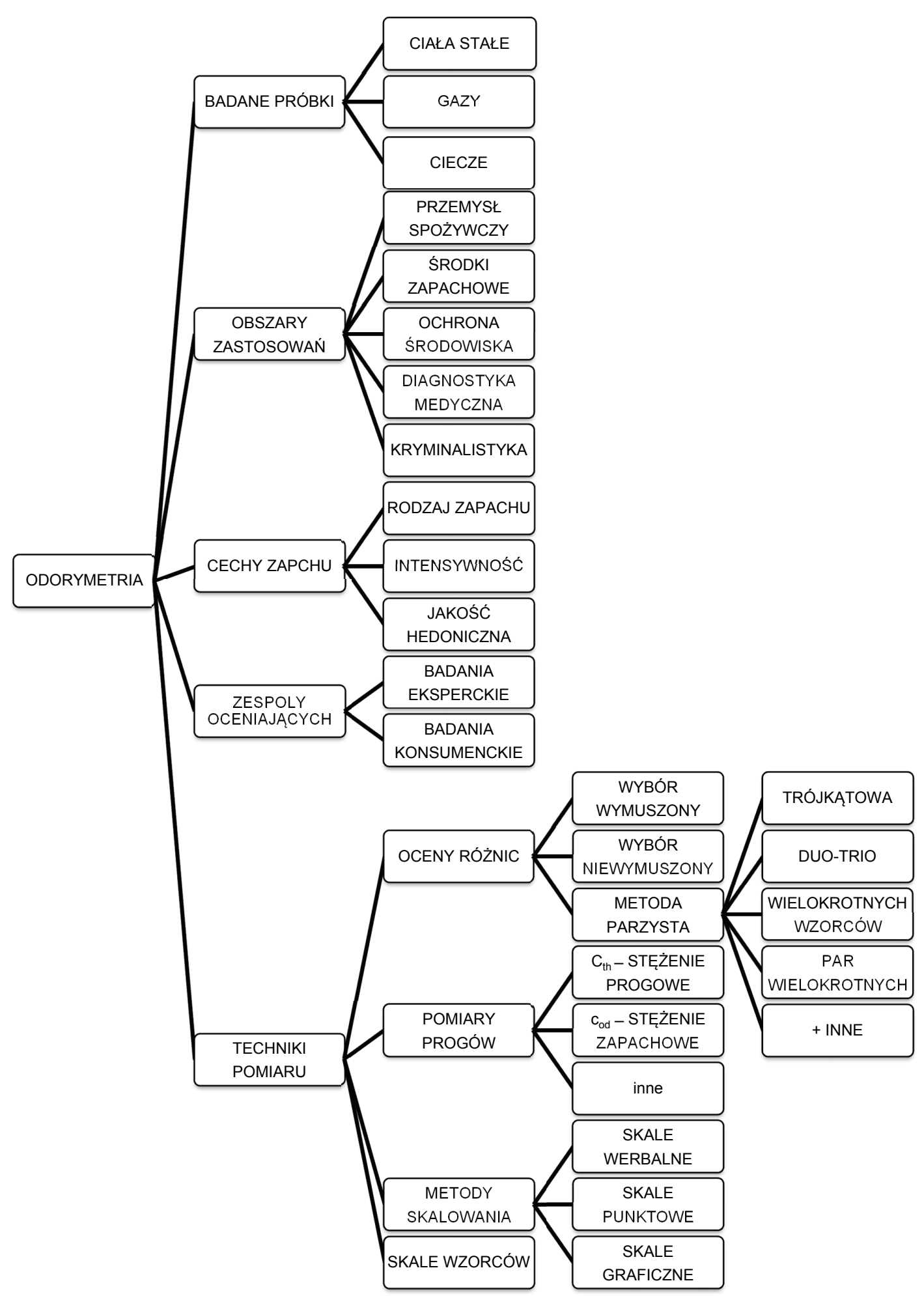

Rys. 1. Przegląd technik, metod oraz obszarów zastosowań pomiarów odorymetrycznych [2]

twórczej substancji wiodącej w mieszaninie gazowej; do oznaczania odorotwórczych związków siarki stosowane są głównie metody opisane np. w pracy I. Sówki [8]).

- olfaktometria dynamiczna (ilościowa identyfikacja substancji zapachowych przez określenie stężenia zapachowego).

Ogólnoświatowym trendem poszukiwania nowych metod badania zapachu odorantów są techniki polegające na kojarzeniu znanych już technologii czy technik pomiarowych, np. wielowymiarowej chromatografii gazowej - spektrometrii masowej i oflaktometrii (MD-GC-MSO).

Zasadniczo metody pomiaru zapachu można podzielić na dwie grupy:

- metody sensoryczne, opierające się na ocenie wrażeń zapachowych odbieranych przez ludzki zmysł powonienia, których wyniki przedstawiane są zwykle w postaci inten- 
sywności zapachowej, stężenia progowego czy stężenia zapachowego,

- metody instrumentalne pozwalające na pomiar stężenia poszczególnych składników mieszaniny gazowej, odpowiedzialnych za jej zapach. Wśród metod tych wyróżnia się przede wszystkim chromatografię gazową sprzężoną z olfaktometrią.

Określenie ,analiza sensoryczna” dotyczy pomiarów wykonywanych w sposób gwarantujący powtarzalność i odtwarzalność wyników. Jest to możliwe w przypadku rygorystycznego przestrzegania procedur szczegółowo opisanych w odpowiednich normach krajowych lub wytycznych resortowych [np. 10, 11, 12]. Precyzują one wymagania, które powinny spełniać zespoły osób oceniających zapach, odczynniki i sprzęt laboratoryjny oraz instalacje wentylacyjno-klimatyzacyjne. Określają także metody sprawdzania sensorycznej wrażliwości uczestników pomiarów, sposób prezentacji próbek i rejestracji wyników ocen czy metody statystycznego opracowania wyników.

Pomiarem zapachowych właściwości substancji zajmuje się dział analizy sensorycznej określany terminem „odorymetria” lub „olfaktometria”. Metody pomiarów odorymetrycznych klasyfikuje się z uwzględnieniem różnego rodzaju kryteriów, np: rodzaj badanych próbek (pochodzenie, stan skupienia), mierzone właściwości zapachu, cel pomiarów lub stosowane techniki. Zakres zastosowań odorymetrii, techniki i przyporządkowane im metody pomiarów odorymetrycznych, jak również mierzone parametry, obrazuje rysunek 1 .

\section{Wytyczne poboru próbek powietrza atmosferycznego}

Określenie metody poboru próbek i zebranie informacji o procesie technologicznym ma decydujące znaczenie dla interpretacji wyników oraz formułowania wniosków z przeprowadzanych badań. Pobór próbek ma bardzo istotny wpływ na występowanie oraz wielkość i zakres błędów pomiarowych. Błędy te wynikać mogą z charakteru źródła (np. w przypadku źródeł niezorganizowanych lub inaczej powierzchniowych, m.in.: oczyszczalnie ścieków, kompostownie) oraz stosowanego sprzętu. Dlatego istotne jest, aby w odniesieniu do konkretnego typu źródła emisji (rysunek 2) określić odpowiedni sposób poboru próbki, w celu dokonania oznaczenia stężenia zapachu z zastosowaniem olfaktometrii dynamicznej czy odorymetrii.

Najważniejszą i kluczową kwestią podczas poboru próbek powietrza jest dbałość o to, aby były one reprezenta- tywne pod względem zapachu $[10,13]$. Uciążliwość zapachowa jest w dużym stopniu związana ze zmiennością stężenia substancji odorotwórczej w czasie. Toteż istotny jest taki pobór próbek powietrza, aby uchwycić maksymalną wartość stężenia odorantów. Kolejny problem towarzyszący poborowi to zebranie wymaganej liczby próbek, niezbędnej do właściwego scharakteryzowania źródła emisji. Bardzo często w przypadku gazów ciepłych czynnikiem przeszkadzającym jest obecność dużych ilości pary wodnej, która podczas pobierania próbki może ulec kondensacji. Z tego względu próbki gazowe o wysokiej zawartości pary wodnej powinny być podczas ich pobierania wstępnie rozcieńczane (w odpowiednim stosunku) czystym, bezwonnym i suchym powietrzem lub azotem.

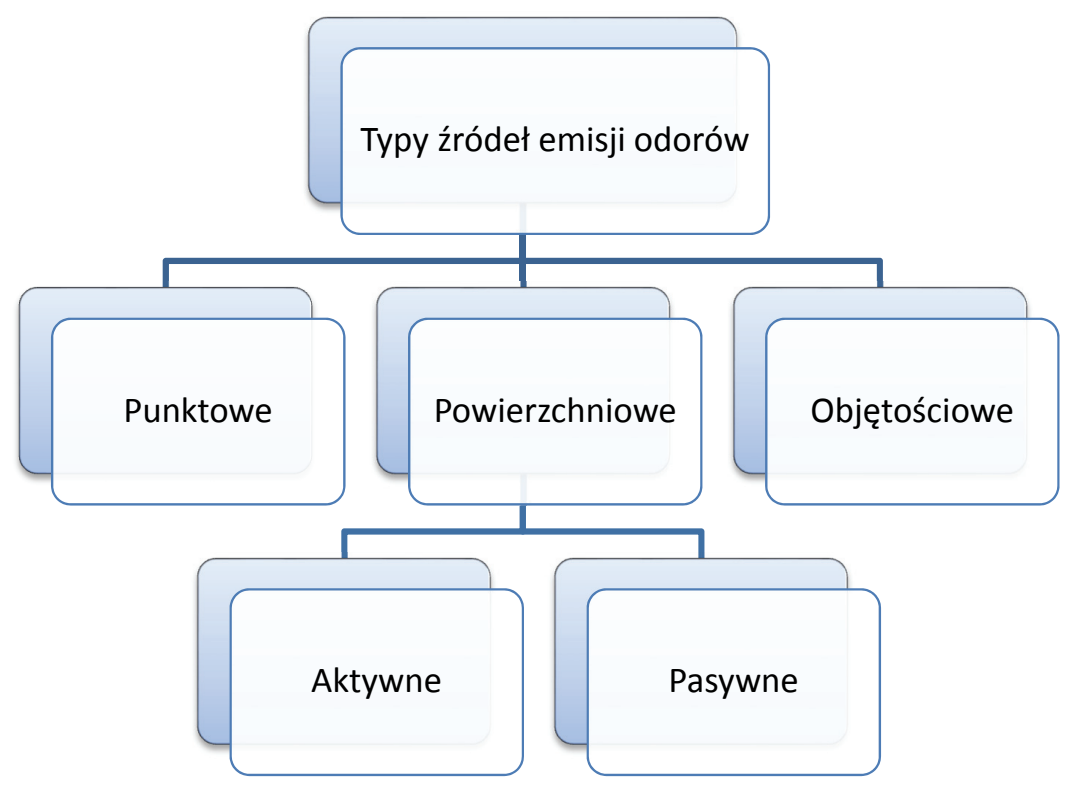

Rys. 2. Podział źródeł emisji odorów [8] 


\section{Badania odorymetryczne INiG - PIB syntetycznych próbek powietrza atmosferycznego}

Badania odorymetryczne jakości zapachowej powietrza prowadzono dla próbek syntetycznych. Przygotowano 4 próbki gazu, zawierające wybrane odorotwórcze związki siarki, odpowiedzialne za uciążliwość zapachową powietrza. Do badań wytypowano najpowszechniej występujące w powietrzu atmosferycznym odoranty siarkowe, będące przyczyną uciążliwości zapachowej, tj. siarkowodór $\left(\mathrm{H}_{2} \mathrm{~S}\right)$ i merkaptan metylowy $\left(\mathrm{CH}_{3} \mathrm{SH}, \mathrm{MeSH}\right)$. W celu dokonania porównania, analogicznym badaniom poddano również tetrahydrotiofen $\left(\mathrm{C}_{4} \mathrm{H}_{8} \mathrm{~S}\right.$, THT), stosowany do nawaniania paliw gazowych, z racji szerokich doświadczeń zespołu ekspertów Zakładu WN w badaniach odorymetrycznych jego zapachu. Zawartość związków siarki w analizowanych próbkach dostosowano do średniej koncentracji tych związków w powietrzu atmosferycznym zanieczyszczonym odorami.

Stężenie związków siarki w poszczególnych próbkach oznaczono przy użyciu analizatora chromatograficznego MEDOR 8000, wyposażonego w detektor elektrochemiczny, zgodnie z wewnętrzną procedurą INiG - PIB oznaczania związków siarki w gazach [4]. Matrycą przygotowanych próbek był azot. Skład oraz stężenie odorantów w przygotowanych próbkach przedstawiono w tablicy 1 .

Tablica 1. Próbki syntetyczne powietrza atmosferycznego przygotowane do badań odorymetrycznych

\begin{tabular}{|c|l|}
\hline Lp. & \multicolumn{1}{|c|}{ Skład mieszaniny } \\
\hline 1. & Siarkowodór $\mathrm{H}_{2} \mathrm{~S}-3,4 \pm 0,2 \mathrm{mg} / \mathrm{m}^{3}$ \\
\hline 2. & Merkaptan metylowy $\mathrm{CH}_{3} \mathrm{SH}-4,0 \pm 0,2 \mathrm{mg} / \mathrm{m}^{3}$ \\
\hline 3. & Tetrahydrotiofen $\mathrm{C}_{4} \mathrm{H}_{8} \mathrm{~S}(\mathrm{THT})-23,3 \pm 1,1 \mathrm{mg} / \mathrm{m}^{3}$ \\
\hline & $\begin{array}{l}\text { Siarkowodór } \mathrm{H}_{2} \mathrm{~S}-1,11 \pm 0,05 \mathrm{mg} / \mathrm{m}^{3} \\
\text { Merkaptan metylowy } \mathrm{CH}_{3} \mathrm{SH}-1,40 \pm 0,07 \mathrm{mg} / \mathrm{m}^{3} \\
\text { Tetrahydrotiofen } \mathrm{C}_{4} \mathrm{H}_{8} \mathrm{~S}(\mathrm{THT})-7,5 \pm 0,4 \mathrm{mg} / \mathrm{m}^{3}\end{array}$ \\
\hline
\end{tabular}

Badania zapachowej jakości próbek powietrza stanowią kontynuację odorymetrycznych badań jakości zapachu gazów przy użyciu układu analitycznego, w postaci przystawki odorymetrycznej INiG - PIB sprzężonej $\mathrm{z}$ chromatografem gazowym lub analizatorem chromatograficznym (np. MEDOR), umożliwiającego wykonywanie równoległych analiz składu próbki oraz intensywności jej zapachu [4]. Zasadę działania oraz schemat ideowy analizatora typu MEDOR przedstawiono we wcześniejszej publikacji autorów [3], w której opisano również zasadę prowadzenia ww. pomiarów równoległych. Pomiary odorymetryczne prowadzono przy użyciu skonstruowanego w INiG - PIB odorymetru (tzw. Odorymetru INiG - PIB [4]). W badaniach uczestniczyła grupa ekspertów Zakładu Nawaniania Paliw Gazowych INiG - PIB.
Badania intensywności zapachu próbek syntetycznych powietrza atmosferycznego w mieszaninie z czystym powietrzem prowadzono dla trzech poziomów stężeń analizowanego gazu: $1 \%, 1,5 \%$ oraz $2 \%$. Wyniki przeprowadzonych badań przedstawiono w tablicach 2, 3, 4 i 5 .

Tablica 2. Wyniki badań odorymetrycznych syntetycznej próbki powietrza atmosferycznego nr 1 - zawierającej siarkowodór

\begin{tabular}{|c|c|c|c|}
\hline \multirow{2}{*}{$\begin{array}{l}\text { Zawartość gazu bada- } \\
\text { nego (próbki powie- } \\
\text { trza syntetycznego) } \\
\text { w mieszaninie z czy- } \\
\text { stym powietrzem }\end{array}$} & \multicolumn{3}{|c|}{ Intensywność zapachu według ekspertów } \\
\hline & ekspert 1 & ekspert 2 & ekspert 3 \\
\hline $1,0 \%$ & $\mathrm{I}=1$ & $I=2$ & $I=2$ \\
\hline $1,5 \%$ & $I=2$ & $I=3$ & $I=3$ \\
\hline $2,0 \%$ & $\mathrm{I}=4$ & $I=5$ & $I=5$ \\
\hline
\end{tabular}

Tablica 3. Wyniki badań odorymetrycznych syntetycznej próbki powietrza atmosferycznego $\mathrm{nr} 2$ - zawierającej merkaptan metylowy

\begin{tabular}{|c|c|c|c|}
\hline $\begin{array}{c}\text { Zawartość gazu bada- } \\
\text { nego (próbki powie- } \\
\text { trza syntetycznego) } \\
\begin{array}{c}\text { w mieszaninie z czy- } \\
\text { stym powietrzem }\end{array}\end{array}$ & \multicolumn{3}{|c|}{ Intensywność zapachu według ekspertów } \\
\cline { 2 - 4 } & ekspert 1 & ekspert 2 & ekspert 3 \\
\hline $1,0 \%$ & $\mathrm{I}=2$ & $\mathrm{I}=3$ & $\mathrm{I}=3$ \\
\hline $1,5 \%$ & $\mathrm{I}=3$ & $\mathrm{I}=4$ & $\mathrm{I}=4$ \\
\hline $2,0 \%$ & $\mathrm{I}=5$ & $\mathrm{I}=5$ & $\mathrm{I}=5$ \\
\hline
\end{tabular}

Tablica 4. Wyniki badań odorymetrycznych syntetycznej próbki powietrza atmosferycznego $\mathrm{nr} 3$ - zawierającej tetrahydrotiofen

\begin{tabular}{|c|c|c|c|}
\hline $\begin{array}{c}\text { Zawartość gazu bada- } \\
\text { nego (próbki powie- } \\
\text { trza syntetycznego) }\end{array}$ & \multicolumn{3}{|c|}{ Intensywność zapachu według ekspertów } \\
\cline { 2 - 4 } $\begin{array}{c}\text { w mieszaninie z czy- } \\
\text { stym powietrzem }\end{array}$ & ekspert 1 & ekspert 2 & ekspert 3 \\
\hline $1,0 \%$ & $\mathrm{I}=2$ & $\mathrm{I}=2$ & $\mathrm{I}=2$ \\
\hline $1,5 \%$ & $\mathrm{I}=3$ & $\mathrm{I}=3$ & $\mathrm{I}=3$ \\
\hline $2,0 \%$ & $\mathrm{I}=4$ & $\mathrm{I}=5$ & $\mathrm{I}=5$ \\
\hline
\end{tabular}

Tablica 5. Wyniki badań odorymetrycznych syntetycznej próbki powietrza atmosferycznego $\mathrm{nr} 4$ - zawierającej siarkowodór, merkaptan metylowy, tetrahydrotiofen

\begin{tabular}{|c|c|c|c|}
\hline \multirow{2}{*}{$\begin{array}{l}\text { Zawartość gazu bada- } \\
\text { nego (próbki powie- } \\
\text { trza syntetycznego) } \\
\text { w mieszaninie z czy- } \\
\text { stym powietrzem }\end{array}$} & \multicolumn{3}{|c|}{ Intensywność zapachu według ekspertów } \\
\hline & ekspert 1 & ekspert 2 & ekspert 3 \\
\hline $1,0 \%$ & $I=2$ & $I=2$ & $\mathrm{I}=2$ \\
\hline $1,5 \%$ & $I=3$ & $I=3$ & $I=3$ \\
\hline $2,0 \%$ & $I=3$ & $I=3$ & $I=4$ \\
\hline
\end{tabular}


Na podstawie otrzymanych wyników zauważyć można ich wysoką odtwarzalność. Efekty pomiaru intensywności zapachu próbki o danym składzie mieszaniny, ocenianej węchowo przez poszczególnych ekspertów, nie różnią się o więcej niż jeden stopień intensywności zapachu (ocena według pięciostopniowej skali intensywności zapachu, zgodnie z ST-IGG 0704:2014 [12]). Na podstawie otrzymanych wyników zauważyć można różnice $\mathrm{w}$ intensywności zapachu uzyskane dla tej samej zawartości danego związku siarki w czystym powietrzu obecnego w różnych próbkach. Jest to efektem różnych wartości granic wyczuwalności zapachu poszczególnych związków siarki oraz odmiennej charakterystyki zapachowej otrzymanych mieszanin gazowych. Tetrahydrotiofen i siarkowodór posiadają wyższą granicę wyczuwalności w porównaniu z merkaptanem metylowym, co odzwierciedlają wyniki badań otrzymane w badanym układzie.

\section{Podsumowanie}

Przedstawiona praca była pierwszą próbą usystematyzowania wiedzy na temat badań zapachowej jakości powietrza atmosferycznego, przy użyciu Odorymetru INiG - PIB. W wyniku jej realizacji dokonano przeglądu literatury dotyczącej najbardziej uciążliwych źródeł odorów, a także metod badawczych oceny jakości zapachowej powietrza. Zrealizowano także serię badań odorymetrycznych syntetycznych próbek powietrza atmosferycznego zawierających organiczne związki siarki o dużym potencjale odorotwórczym, przy udziale grupy ekspertów Zakładu Nawaniania Paliw Gazowych INiG - PIB. Otrzymane wyniki charakteryzowały się zadowalającą odtwarzalnością. Jednym z najważniejszych osiągnięć tej pracy jest rozszerzenie możliwości aplikacyjnych opracowanej przez INiG - PIB przystawki odorymetrycznej (Odorymetru INiG - PIB) na obszar kontroli zapachowej jakości powietrza atmosferycznego.

Prosimy cytować jako: Nafta-Gaz 2016, nr 7, s. 539-544, DOI: 10.18668/NG.2016.07.07

Artykuł nadesłano do Redakcji 9.12.2015 r. Zatwierdzono do druku 8.04.2016 r.

Artykuł powstał na podstawie pracy statutowej pt. Badanie zależności zapachowej jakości powietrza od zawartości zanieczyszczeń siarkowych z użyciem przystawki odorymetrycznej INiG - PIB - praca INiG - PIB na zlecenie MNiSW; nr zlecenia: 0054/ WN/15/01, nr archiwalny: DK-4100-54/15.

\section{Literatura}

[1] Huszał A.: Usuwanie THT z nawonionego gazu ziemnego, rozprowadzonego siecia przesyłowa, z użyciem sorbentów ciektych. Nafta-Gaz 2010, nr 5, s. 373-378.

[2] Kośmider J., Mazur-Chrzanowska B., Wyszyński B.: Odory. Wydawnictwo Naukowe PWN, Warszawa 2002, s. 92-132.

[3] Lisman Sz., Huszał A.: Badania jakości zapachu gazów ziemnych przy uzyciu przystawki odorymetrycznej INiG - PIB sprzężonej z analizatorem chromatograficznym wyposażonym $w$ detektor elektrochemiczny. Nafta-Gaz 2015, nr 12, s. $13-17$.

[4] Lisman Sz., Huszał A.: Dostosowanie prototypu przystawki odorymetrycznej sprzężonej z chromatografem gazowym do oznaczeń zapachowej jakości gazów. Nafta-Gaz 2015, nr 3, s. $190-194$

[5] Makles Z., Galwas-Zakrzewska M.: Złowonne gazy w środowisku pracy. Bezpieczeństwo Pracy 2005, nr 9, s. 12-16.

[6] Piskowska-Wasiak J.: Emisja zanieczyszczeń gazowych w procesie odsiarczania gazu ziemnego metoda IGNiG-Chelate. Nafta-Gaz 2012, nr 3, s. 191-201.

[7] Portal Samorządowy: http://www.portalsamorzadowy.pl/

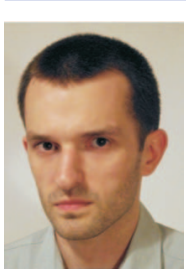

Mgr inż. Szymon LISMAN

Specjalista inżynieryjno-techniczny w Zakładzie

Nawaniania Paliw Gazowych.

Instytut Nafty i Gazu - Państwowy Instytut Badawczy

ul. Lubicz 25 A

31-503 Kraków

E-mail:szymon.lisman@inig.pl gospodarka-komunalna/zamiast-ustawy-antyodorowejpowstanie-kodeks-dobrych-praktyk-dla-samorzadow,69403. html (dostęp: wrzesień 2015).

[8] Sówka I.: Metody identyfikacji odorotwórczych gazów emitowanych z obiektów przemysłowych. Prace Naukowe Instytutu Inżynierii Ochrony Środowiska Politechniki Wrocławskiej 2011, nr 90 (55), s. 21-42.

[9] Szlęk M., Holewa J.: Optymalizacja metody oznaczania zawartości związów siarki występujących w paliwach gazowych. Nafta-Gaz 2015, nr 5, s. 308-313.

\section{Akty prawne i normatywne:}

[10] PN-EN 13725: 2007 Jakość powietrza. Oznaczanie stężenia zapachowego metoda olfaktometrii dynamicznej.

[11] PN-EN ISO 8586:2014-03 Analiza sensoryczna. Ogólne wytyczne wyboru, szkolenia i monitorowania wybranych oceniajacych i ekspertów oceny sensorycznej.

[12] ST-IGG 0704:2014 Nawanianie paliw gazowych. Kontrola nawaniania paliw gazowych metodami odorymetrycznymi.

[13] VDI 3880: 2011 Olfactometry - Static sampling.

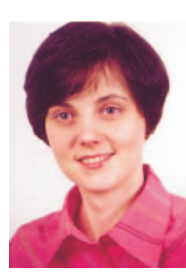

Dr Anna HUSZAI

Adiunkt; kierownik Zakładu Nawaniania Paliw Gazowych.

Instytut Nafty i Gazu - Państwowy Instytut Badawczy ul. Lubicz 25 A

31-503 Kraków

E-mail: anna.huszal@inig.pl 